\title{
Nonlinear effect on wave loads of large ships in time domain
}

\author{
Mun-Sung Kim, Jong-Jin Park, Byung-Woo Kim and Jae-Kwang Eom \\ Offshore Technology Research, Marine Research Institute, Samsung Heavy Industries, Co. Ltd., Gyeong-Nam, Korea
}

\begin{abstract}
As sea state harsher in the ocean space, more large motion and wave loads occurs on ships hull by non-linear phenomena. To consider nonlinear effect on ships hull in the structural design verification, the direct calculation method with numerical approach is used rather than rule values for the reliable accuracy.

In this paper, the non-linear wave loads analysis in time domain is performed by using a Rankine Panel Method together with numerical schemes. Linear calculations have been carried out based on DNV CSA-2 notation to generate the motion responses and wave loads of large ships. By short and long term analysis, the design wave amplitudes are selected for the nonlinear analysis. The maximum wave induced bending moment in hogging and sagging conditions are calculated in the nonlinear analysis. Also, the green water effect on the wave induced vertical bending moment was investigated. The results show the vertical bending moments are more influenced by green water in sagging condition than in hogging condition due to green water loading.
\end{abstract}

KEY WORDS: Nonlinear; Wave Loads; Motion; Green water.

\section{INTRODUCTION}

This paper presents the result of the CSA-2 wave loads analysis of two large ships in waves. To produce design loads for input to CSA-2 analysis, the direct wave loads analysis has been carried out. For the accurate analysis of motion and wave loads response of the vessels, a three dimensional ship motion program, WASIM(2004) is used for the sea-keeping analysis. WASIM is developed by DNV, and can solve the linear \& nonlinear ship motion and wave load. Also WAVESHIP(1993) program is used for tuning of the viscous roll damping.

The main objective of this paper is to evaluate the motion responses and wave loads for vessels in various loading conditions as based on DNV CSA-2 notation. The work includes the following tasks:

- Linear WASIM analysis to determine the design loads at 20-year equivalent level of probability in North Atlantic (ULS)

- Calculation of regular design waves for the non-linear analysis for each of the relevant design bending moments

- Linear and non-linear WASIM simulations with the above mentioned design waves to produce external hydrodynamic pressure distribution at snapshots representing the 20-year equivalent events for each of the relevant design loads.

\section{BASIS OF ANALYSIS}

The wave loads analysis has been carried out based on the loading manual, which contains the basic information of hull with hydrostatic data for various loading conditions.

\section{Ship conditions}

Table 1 provides the principal particulars of designed carriers.

Table 1 Principal particulars.

\begin{tabular}{|l|c|c|}
\hline \multicolumn{1}{|c|}{ Ship type } & Ship A & Ship B \\
\hline Length B.P. $(m)$ & 270.0 & 302.0 \\
\hline Breadth, mld. $(m)$ & 43.4 & 50.0 \\
\hline Depth, mld. $(m)$ & 26.0 & 27.0 \\
\hline
\end{tabular}

Fig. 1 shows the photo of designated vessels.
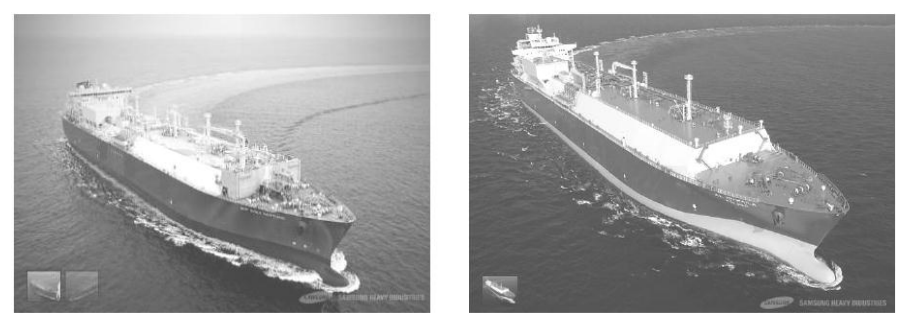

Fig. 1 Photo of two types of ship.
Corresponding author: Mun-Sung Kim

e-mail: munsung.kim@samsung.com 


\section{Loading Conditions}

Table 2 and Fig. 2 show the selected loading conditions as design cases of designed vessels for CSA-2 analysis. Ballast and full load conditions are selected.

Table 2 Loading conditions

\begin{tabular}{|l|c|c|c|c|}
\hline \multicolumn{1}{|c|}{ Ship type } & \multicolumn{2}{|c|}{ Ship A } & \multicolumn{2}{c|}{ Ship B } \\
\hline $\begin{array}{l}\text { Loading } \\
\text { condition }\end{array}$ & Ballast & Full load & Ballast & Full load \\
\hline Draft $(m)$ & 9.704 & 11.851 & 9.660 & 11.978 \\
\hline Disp. $(M T)$ & 85647.1 & 106889.6 & 112713.4 & 143541.9 \\
\hline KG $(m)$ & 12.287 & 16.116 & 12.380 & 17.480 \\
\hline LCG $(m)$ & 135.743 & 134.763 & 149.962 & 146.897 \\
\hline
\end{tabular}

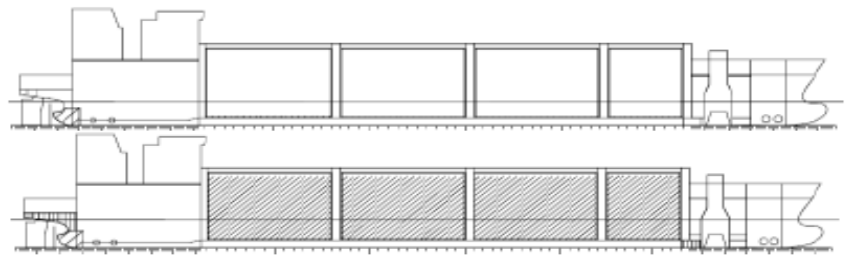

(a) Ship A(Ballast, Full load)

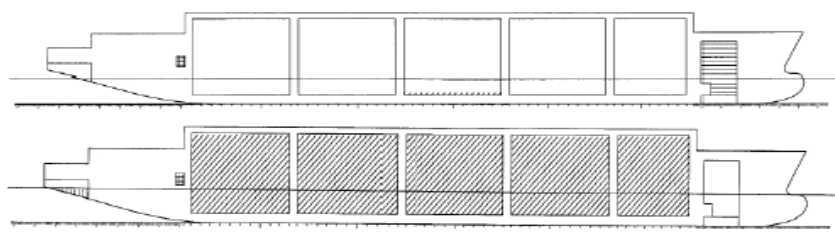

(b) Ship B(Ballast, Full load)

Fig. 2 Selected design cases.

\section{WAVE LOADS ANALYSIS}

The wave loads analysis for the vessels has been performed by using an advanced three-dimensional ship motion program, WASIM(2004), developed by DNV. It is noted that WASIM uses a three-dimensional diffraction theory with various boundary conditions in time domain. In this paper, the following programs are used to obtain the ship motion and wave loads results :

- WASIM(2004), linear and nonlinear three-dimensional time domain program. WASIM in its linear mode calculates RAO (Response Amplitude Operator) for motions, hydrodynamic pressure and sectional forces of the vessel. In its nonlinear mode, time series of the specified responses are generated, and additional FroudeKrylov and hydrostatic forces from wave action above still water level are included. The ship speed effects are accounted for by WASIM. Green water effect is simulated by WASIM as hydrodynamic loads on deck using a non-linear Froude Krylov pressure. The simulation of green water flow on deck is coupled with the ship motion in waves.

- WAVESHIP (1993), linear two-dimensional frequency domain program. WAVESHIP is applied for calculation of viscous roll damping.

- POSTRESP (2004), wave statistical post-processor for determination of short and long term responses of motion and wave loads.

\section{Co-ordinate system}

Fig. 3 shows the right-hand co-ordinate system of ship motion. The ship motions have been calculated at the center of gravity of the ship. The positive heave is upward, and the positive pitch is bow downward.

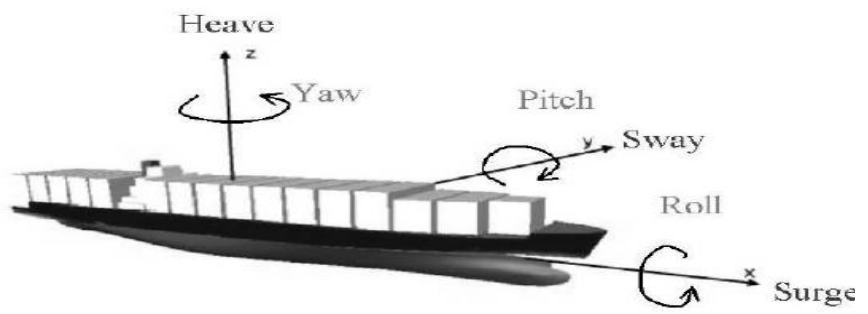

Fig. 3 Co-ordinate system of ship motion.

The co-ordinate system of global wave loads is shown in Fig. 4. The sign conventions for wave loads in a transverse cut are as follows:

- Vertical shear force : positive in applying an upward force forward of the cut and a downward force after of the cut.

- Vertical bending moment : positive for sagging and negative for hogging.

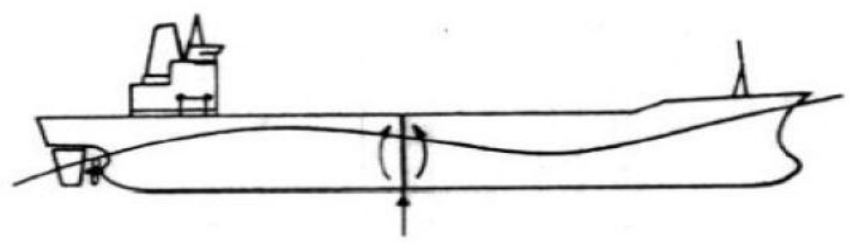

Fig. 4 Co-ordinate system of wave loads.

\section{Hull geometry and mass modeling}

In order to carry out the numerical analysis for ship motion and wave loads, the ship and the free surface are modeled by a number of quadrilateral panels for the hull surface from the lines and offset table. According to WASIM (2004), it was found from the convergence study that $40 \times 12$ panels or some more for the half of the ship considering a symmetry condition of port and starboard side wetted surface are sufficient for accurate solutions. Fig. 5 and Table 3 show the panel arrangements and mesh numbers including time steps. The input mass is modeled by using FE method, not by point mass method for the direct load transfer from the hydrodynamic model to structure model. 


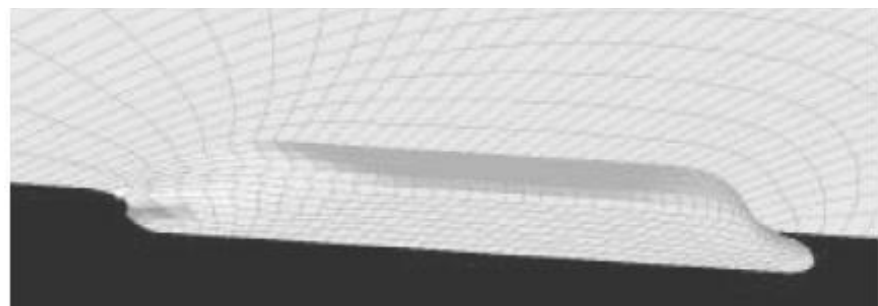

(a) Ship A

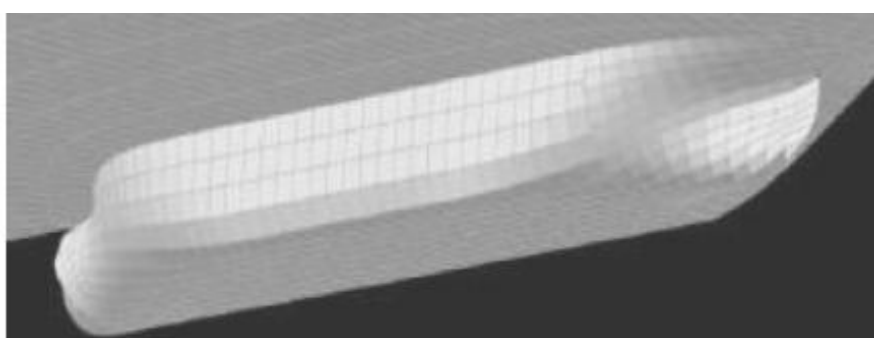

(b) Ship B

Fig. 5 Panel arrangement.

Table 3 Mesh numbers and time steps.

\begin{tabular}{|c|c|c|}
\hline Ship type & Ship A & Ship B \\
\hline Free surface (no.) & 1638 & 2730 \\
\hline Body (no.) & 588 & 731 \\
\hline Free surface type & O-type grid & O-type grid \\
\hline Free surface size & $5 \times \mathrm{Lbp}$ & $5 \times \mathrm{Lbp}$ \\
\hline Time step (s) & 0.08 & 0.08 \\
\hline Duration (s) & 800.0 & 800.0 \\
\hline
\end{tabular}

\section{Environmental condition}

The environmental conditions of vessels for ULS are shown in Table 4. The scatter diagram of North Atlantic wave is selected from the DNV-RP-C205(2007) for the ULS analysis. An advance forward speed of 5.0 knots is considered for the ultimate strength analysis. The wave heading angles are equally distributed from 0 to 360 degrees with 30 degrees interval. The wave loads are calculated at a return period of 20 years.

\section{Calculation condition}

For the generation of motion and wave loads of vessels, the calculation conditions such as wave heading angles, periods and forward speed etc should be defined. The purpose of linear analysis is to produce RAOs for the design loads relevant for CSA-2 and to determine 20 years equivalent values through post processing.

The wave heading angles and periods are shown in Table 5.

Table 5 Wave heading angles and periods in ULS.

\begin{tabular}{|c|c|}
\hline $\begin{array}{c}\text { Wave heading } \\
(\text { deg. })\end{array}$ & 0.0 to 360.0, interval 30.0 \\
\hline & $\begin{array}{c}4.0,5.0,6.0,7.0,8.0,9.0,10.0,11.0, \\
\text { Wave periods } \\
(s)\end{array}$ \\
$\begin{array}{c}12.0,13.0,14.0,15.0,16.0,18.0,20.0, \\
22.0,25.0,30.0,35.0\end{array}$ \\
\hline
\end{tabular}

The forward speeds for ULS analysis is as follows,

- for ULS : 5.0 knots

Table 4 Scatter diagram for the North Atlantic wave(DNV, 2007).

\begin{tabular}{|c|c|c|c|c|c|c|c|c|c|c|c|c|c|c|c|c|c|c|c|}
\hline hs ltz & 1.5 & 2.5 & 3.5 & 4.5 & 5.5 & 6.5 & 7.5 & 8.5 & 9.5 & 10.5 & 11.5 & 12.5 & 13.5 & 14.5 & 15.5 & 16.5 & 17.5 & 18.5 & SUM \\
\hline 0.5 & 0.0 & 0.0 & 1.3 & 133.7 & 865.6 & 1186.0 & 634.2 & 186.3 & 36.9 & 5.6 & 0.7 & 0.1 & 0.0 & 0.0 & 0.0 & 0.0 & 0.0 & 0.0 & 3050 \\
\hline 1.5 & 0.0 & 0.0 & 0.0 & 29.3 & 986.0 & 4976.0 & 7738.0 & 5569.7 & 2375.7 & 703.5 & 160.7 & 30.5 & 5.1 & 0.8 & 0.1 & 0.0 & 0.0 & 0.0 & 22575 \\
\hline 2.5 & 0.0 & 0.0 & 0.0 & 2.2 & 197.5 & 2158.8 & 6230.0 & 7449.5 & 4860.4 & 2066.0 & 644.5 & 160.2 & 33.7 & 6.3 & 1.1 & 0.2 & 0.0 & 0.0 & 23810 \\
\hline 3.5 & 0.0 & 0.0 & 0.0 & 0.2 & 34.9 & 695.5 & 3226.5 & 5675.0 & 5099.1 & 2838.0 & 1114.1 & 337.7 & 84.3 & 18.2 & 3.5 & 0.6 & 0.1 & 0.0 & 19128 \\
\hline 4.5 & 0.0 & 0.0 & 0.0 & 0.0 & 6.0 & 196.1 & 1354.3 & 3288.5 & 3857.5 & 2685.5 & 1275.2 & 455.1 & 130.9 & 31.9 & 6.9 & 1.3 & 0.2 & 0.0 & 13289 \\
\hline 5.5 & 0.0 & 0.0 & 0.0 & 0.0 & 1.0 & 51.0 & 498.4 & 1602.9 & 2372.7 & 2008.3 & 1126.0 & 463.6 & 150.9 & 41.0 & 9.7 & 2.1 & 0.4 & 0.1 & 8328 \\
\hline 6.5 & 0.0 & 0.0 & 0.0 & 0.0 & 0.2 & 12.6 & 167.0 & 690.3 & 1257.9 & 1268.6 & 825.9 & 386.8 & 140.8 & 42.2 & 10.9 & 2.5 & 0.5 & 0.1 & 4806 \\
\hline 7.5 & 0.0 & 0.0 & 0.0 & 0.0 & 0.0 & 3.0 & 52.1 & 270.1 & 594.4 & 703.2 & 524.9 & 276.7 & 111.7 & 36.7 & 10.2 & 2.5 & 0.6 & 0.1 & 2586 \\
\hline 8.5 & 0.0 & 0.0 & 0.0 & 0.0 & 0.0 & 0.7 & 15.4 & 97.9 & 255.9 & 350.6 & 296.9 & 174.6 & 77.6 & 27.7 & 8.4 & 2.2 & 0.5 & 0.1 & 1309 \\
\hline 9.5 & 0.0 & 0.0 & 0.0 & 0.0 & 0.0 & 0.2 & 4.3 & 33.2 & 101.9 & 159.9 & 152.2 & 99.2 & 48.3 & 18.7 & 6.1 & 1.7 & 0.4 & 0.1 & 626 \\
\hline 105 & 0.0 & 0.0 & 00 & 00 & 00 & 00 & 12 & 10.7 & 37.9 & 675 & 71.7 & 515 & 27.3 & 114 & 40 & 12 & 03 & 0.1 & 285 \\
\hline 115 & 0.0 & 0.0 & 00 & 00 & 0.0 & 0.0 & 0.3 & 3.3 & 13.3 & 26.6 & 31.4 & 247 & 142 & 6.4 & 24 & 0.7 & 0.2 & 0.1 & 124 \\
\hline 12.5 & 0.0 & 0.0 & 0.0 & 0.0 & 0.0 & 0.0 & 0.1 & 1.0 & 4.4 & 9.9 & 12.8 & 11.0 & 6.8 & 3.3 & 1.3 & 0.4 & 0.1 & 0.0 & 51 \\
\hline 135 & 0.0 & 00 & 00 & 00 & 0.0 & 0.0 & 0.0 & 0.3 & 14 & 3.5 & 50 & 46 & 3.1 & 16 & 0.7 & 0.2 & 01 & 0.0 & 21 \\
\hline 145 & 0.0 & 00 & 00 & 00 & 0.0 & 0.0 & 00 & 0.1 & 0.4 & 12 & 18 & 18 & 13 & 0.7 & 0.3 & 0.1 & 00 & 0.0 & 8 \\
\hline 155 & 0.0 & 0.0 & 00 & 00 & 0.0 & 0.0 & 00 & 0.0 & 0.1 & 0.4 & 0.6 & 0.7 & 0.5 & 03 & 0.1 & 0.1 & 00 & 0.0 & 3 \\
\hline 165 & 0.0 & 0.0 & 00 & 00 & 0.0 & 0.0 & 0.0 & 0.0 & 0.0 & 0.1 & 0.2 & 0.2 & 0.2 & 0.1 & 0.1 & 0.0 & 00 & 0.0 & 1 \\
\hline Sum & 0 & 0 & 1 & 165 & 2091 & 9280 & 19922 & 24879 & 20870 & 12898 & 6245 & 2479 & 837 & 247 & 66 & 16 & 3 & 1 & 100000 \\
\hline
\end{tabular}

The $H s$ and $T z$ values are cell midpoint

\section{Roll tuning}

The linear two-dimensional strip theory program WAVESHIP is used for calculation of damping in roll motion due to viscous effects. The calculated viscous roll damping is subsequently added to the potential damping in the hydrodynamic analysis. The roll tuning is performed at probability levels of 20 years return period for ULS.

The rolling equation of motion is derived as followings; 
$\left(I_{44}+A_{44}\right) \ddot{\xi}_{4}+\left(B_{44}+B_{V 44}\right) \dot{\xi}_{4}+C_{44} \xi_{4}=F_{4}$

where, $I_{44}$ : roll moment of inertia

$A_{44}$ : added roll moment of inertia

$B_{44}$ : wave making damping of roll

$B_{V 44}: \zeta^{*} B_{c r}, B_{c r}:$ critical damping $=2 \sqrt{\left(I_{44}+A_{44}\right) \cdot C_{44}}$

$\zeta$ : damping coefficient

$F_{4}$ : roll exciting force

The detailed results of roll tuning for ULS analysis are shown in Fig. 6.

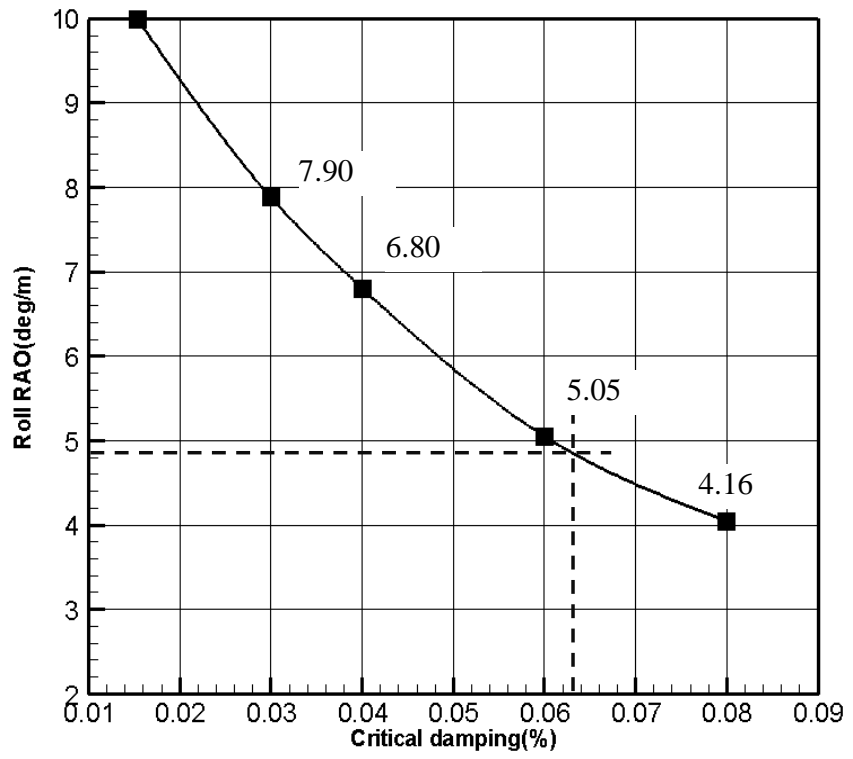

The roll tuning values by numerical method are given in Table 6.

Table 6 Roll tuning for Ultimate Limit State (ULS)

\begin{tabular}{|l|c|c|c|c|}
\hline Ship type & \multicolumn{2}{|c|}{ Ship A } & \multicolumn{2}{c|}{ Ship B } \\
\hline $\begin{array}{l}\text { Loading } \\
\text { condition }\end{array}$ & Ballast & Full load & Ballast & Full load \\
\hline $\begin{array}{l}\text { Critical } \\
\text { damping } \\
(\%), \zeta\end{array}$ & 6.3 & 5.3 & 6.2 & 6.5 \\
\hline
\end{tabular}

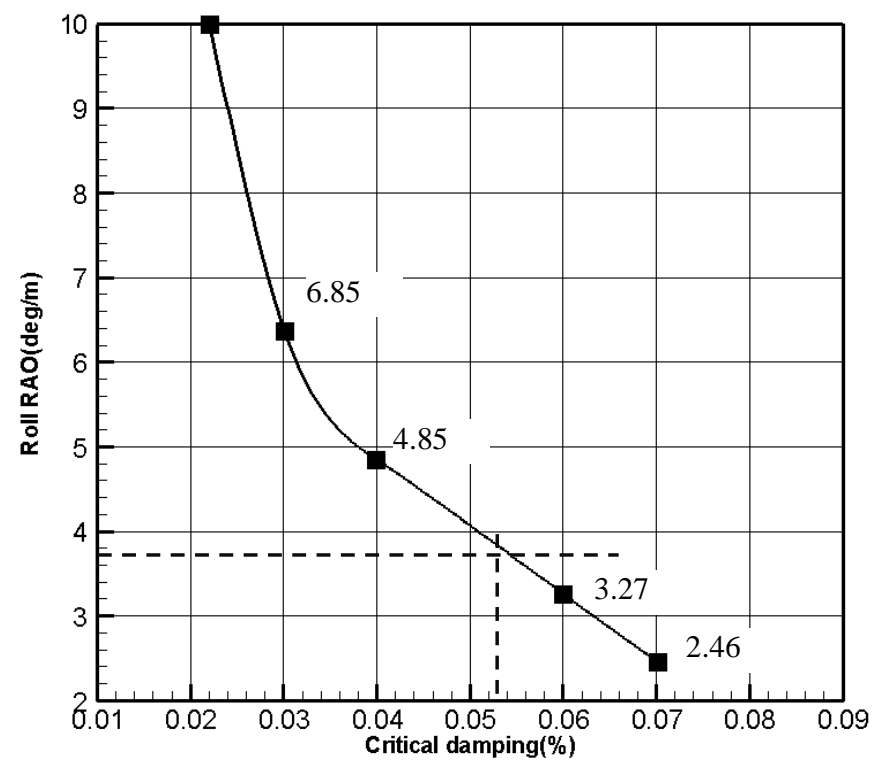

(a) Ship A (Ballast, Full load)
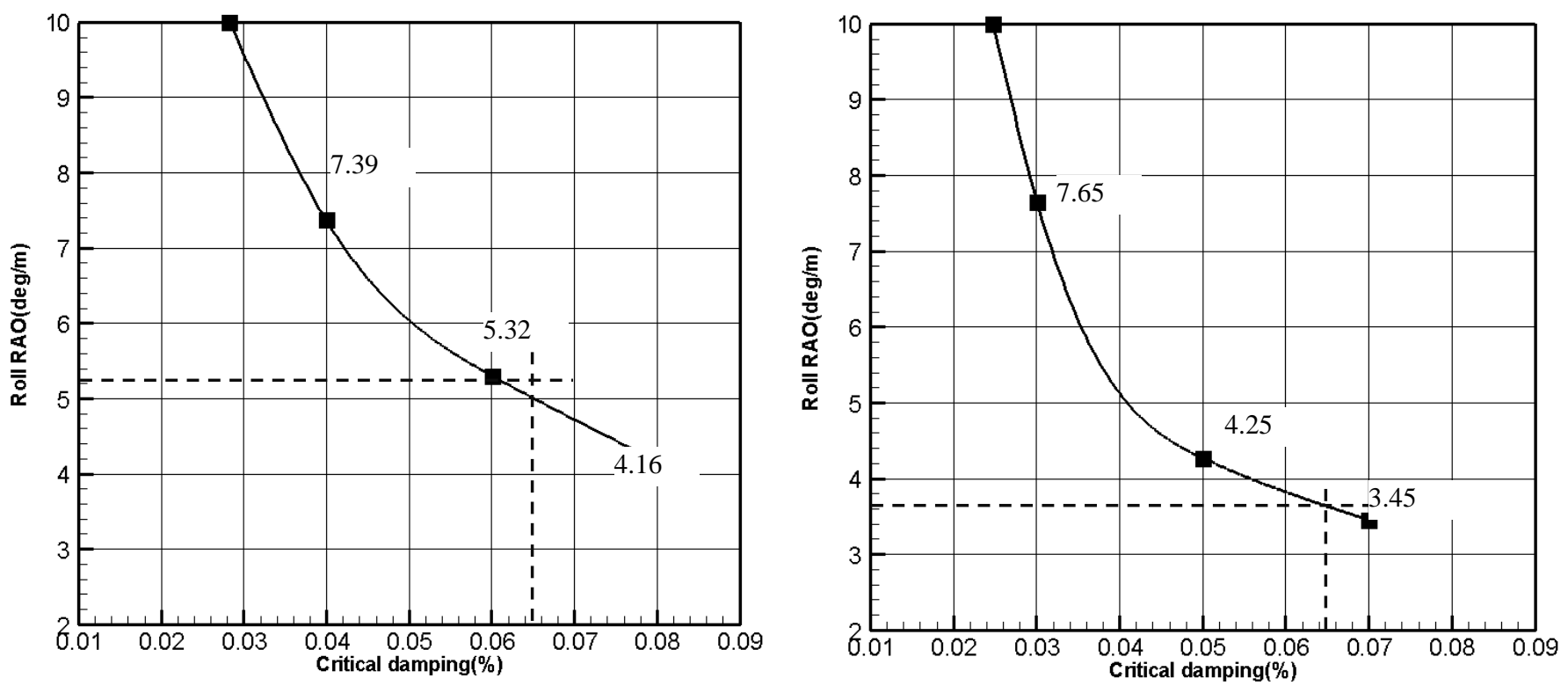

Fig. 6 Roll tuning : ULS analysis.

(b) Ship B (Ballast, Full load) 


\section{Numerical conditions}

In the time domain wave loads analysis using Rankine Panel Method, the various numerical schemes are required to generate the transfer functions of motion and wave loads. Table 7 shows the numerical conditions of linear analysis as well as nonlinear analysis. For non-linear analysis with design wave conditions to generate design loads $200.0 \mathrm{~s}$ time duration is applied.

Table 7 Numerical conditions

\begin{tabular}{|c|c|c|c|}
\hline \multicolumn{2}{|c|}{ Ship type } & Ship A & Ship B \\
\hline \multicolumn{2}{|c|}{ Singularity } & $\begin{array}{c}\text { Rankine } \\
(1 / r)\end{array}$ & $\begin{array}{c}\text { Rankine } \\
(1 / r)\end{array}$ \\
\hline \multicolumn{2}{|c|}{ Integration method } & $1^{s t}$ order & $1^{s t}$ order \\
\hline \multicolumn{2}{|c|}{ Linearization } & Neuman-Kelvin & Neuman-Kelvin \\
\hline \multicolumn{2}{|c|}{ Start-up } & Smooth & Smooth \\
\hline \multicolumn{2}{|c|}{ Analysis-type } & $\begin{array}{c}\text { Linear/ } \\
\text { Froude-Klylov } \\
\text { Non-linear }\end{array}$ & $\begin{array}{c}\text { Linear/ } \\
\text { Froude-Klylov } \\
\text { Non-linear }\end{array}$ \\
\hline \multicolumn{2}{|c|}{ Filter } & 10 & 10 \\
\hline \multirow{3}{*}{$\begin{array}{l}\text { Eigen } \\
\text { period } \\
(s)\end{array}$} & Surge & 100 & 100 \\
\hline & Sway & 0 & 0 \\
\hline & Yaw & 100 & 100 \\
\hline \multirow{3}{*}{$\begin{array}{c}\text { Damping } \\
\text { coeff. } \\
(\%)\end{array}$} & Surge & 50 & 50 \\
\hline & Sway & 0 & 0 \\
\hline & Yaw & 50 & 50 \\
\hline
\end{tabular}

\section{Sectional cuts}

Fig. 13 show the sectional cuts in which the vertical bending moments and shear forces are calculated. Total 25 sections are used for the wave loads calculations.

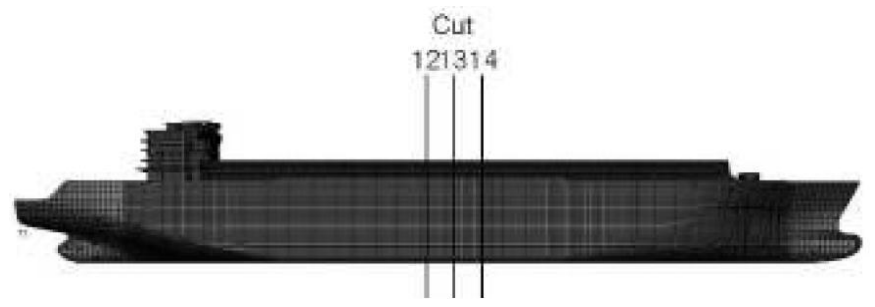

Fig. 7 Definition of sectional cuts for wave loads

\section{Post processing}

The linear transfer functions, RAOs, from the hydrodynamic analysis are post-processed in a short and long term response distribution, based on the following environmental conditions (see Table 8).
Table 8 Post processing condition for Ultimate Limit State (ULS)

\begin{tabular}{|l|l|}
\hline Wave spectrum & Pierson-Moscowitz \\
\hline Heading profile & Equal probability \\
\hline Wave spreading & $\operatorname{Cos}^{2}(\theta)$ \\
\hline Scatter diagram & North Atlantic \\
\hline Probability level & 20 year equivalent \\
\hline
\end{tabular}

\section{RESULTS}

\section{Stillwater bending moments}

WASIM program also calculates the still-water bending moments. However, the still-water bending moments from WASIM differ from the values of result listed in the loading manual. Fig. 8 shows the reason of different still-water bending moments between WASIM and the loading manual.

WASIM includes the hydrostatic end effects of the ship. The static pressure generates a hogging moment. In Fig. 9, the still-water bending moments from the loading manual and WASIM are compared. The pink line denotes the results from the loading manual corrected for the hydrostatic end pressure. The correction is performed in the following way:

$$
\Delta M_{5}=\rho g d \frac{d B}{2}\left(Z_{N, A}-\frac{d}{3}\right)
$$

where, $\rho$ is the water density, $g$ is the acceleration of gravity, $\mathrm{d}$ is the draft, $\mathrm{B}$ is the breadth, and $\mathrm{Z}_{\mathrm{N} . \mathrm{A} \text {. }}$ is the neutral axis.

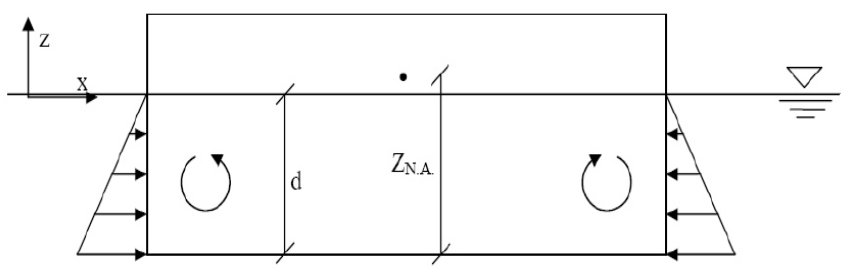

Fig. 8 Schematic figure. of vessel-Hogging moment from hydrostatic pressure.

\section{Transfer functions}

The response amplitude operators of motion and vertical bending moment are shown in Fig. 10 and 11.

\section{Design loads}

The linear and nonlinear vertical bending moments in hogging and sagging conditions are given in Fig. 12. The nonlinear design loads are higher than the linear and rule values in sagging and hogging condition. The larger ship length, the larger nonlinear loads occur on the mid-ship section. 

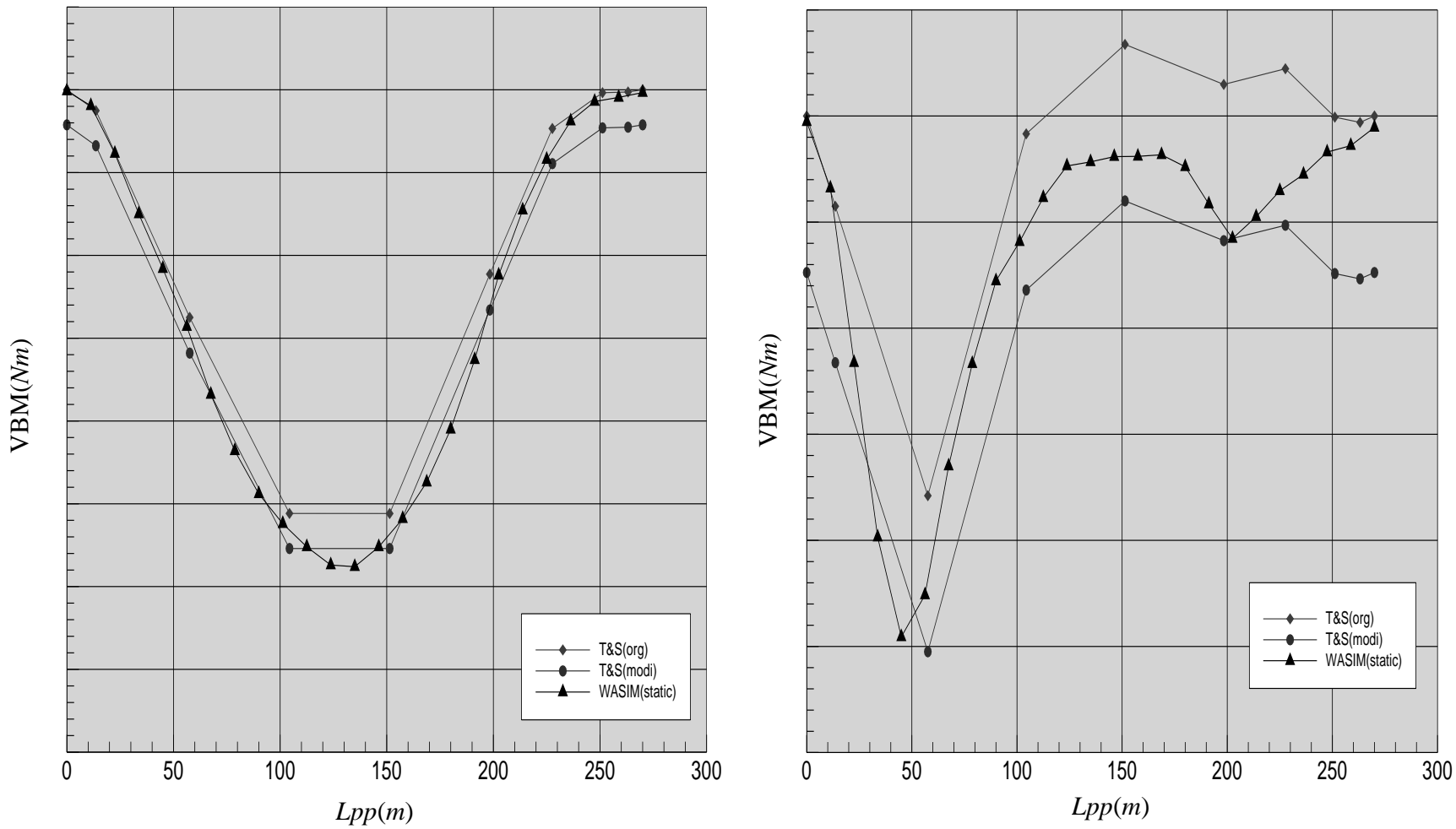

(a) Ship A (ballast, full load)
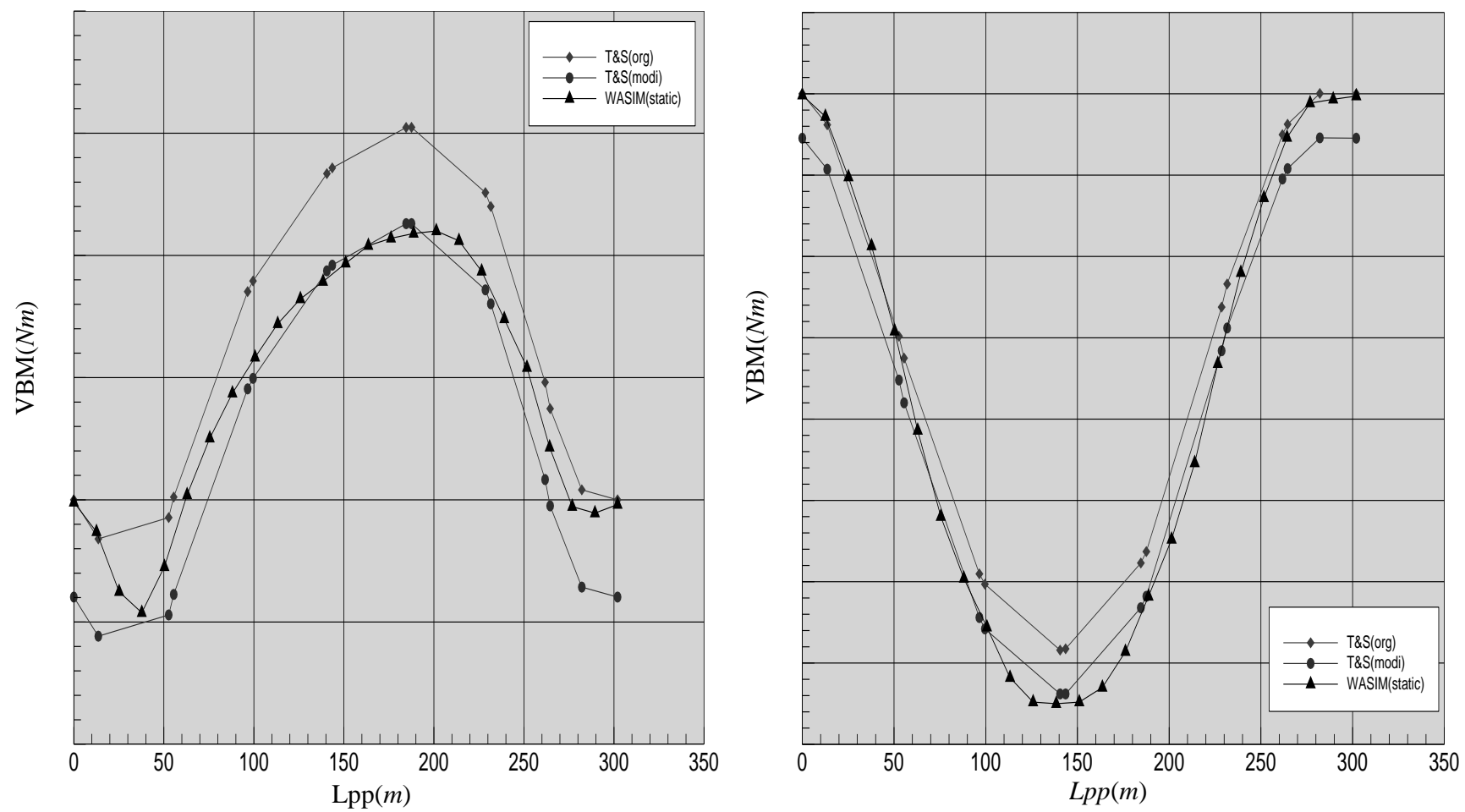

(b) Ship B (ballast, full load)

Fig. 9 Vertical Stillwater bending moment 

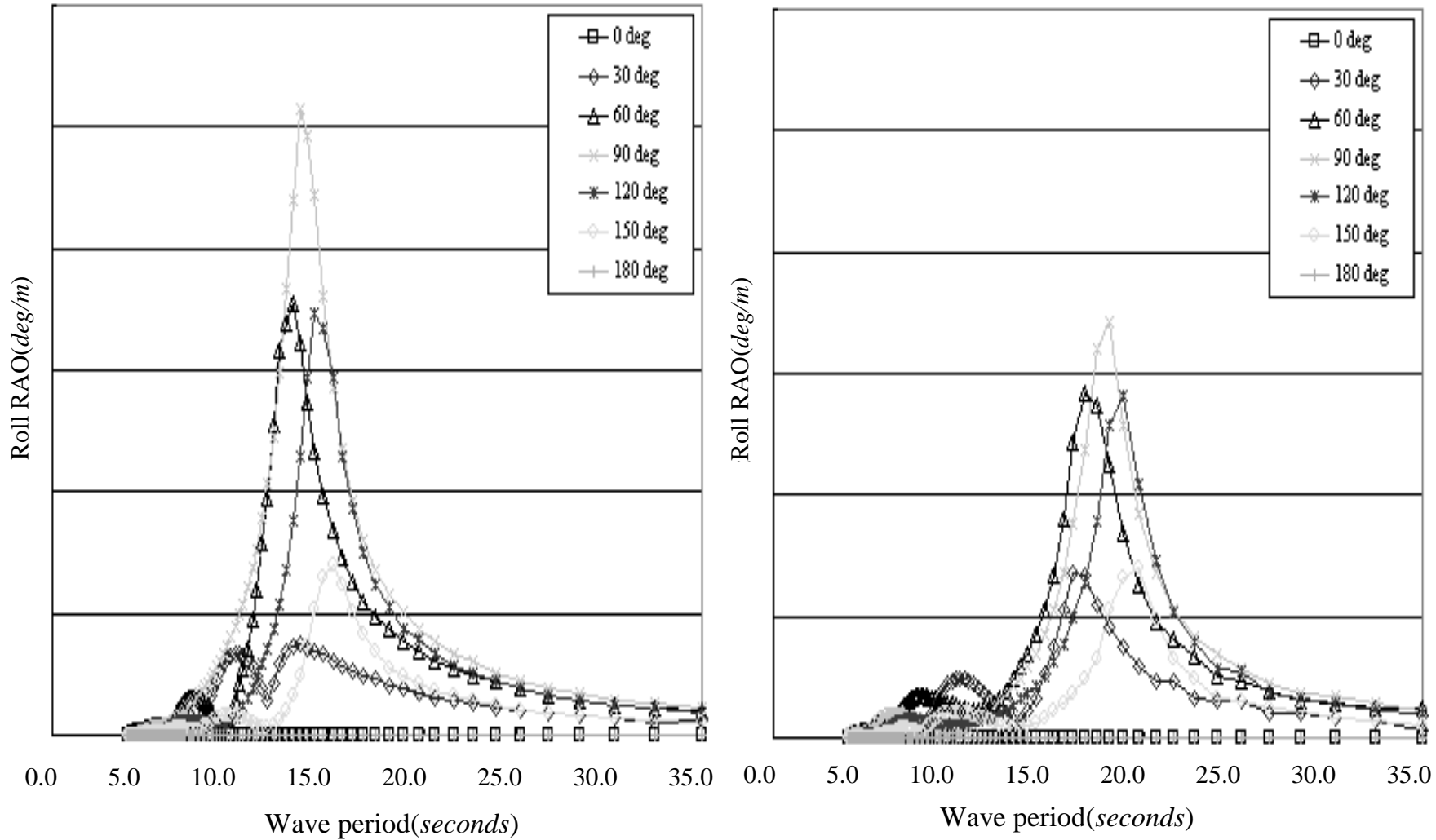

Wave period(seconds)

(a) Ship A (ballast, full load)
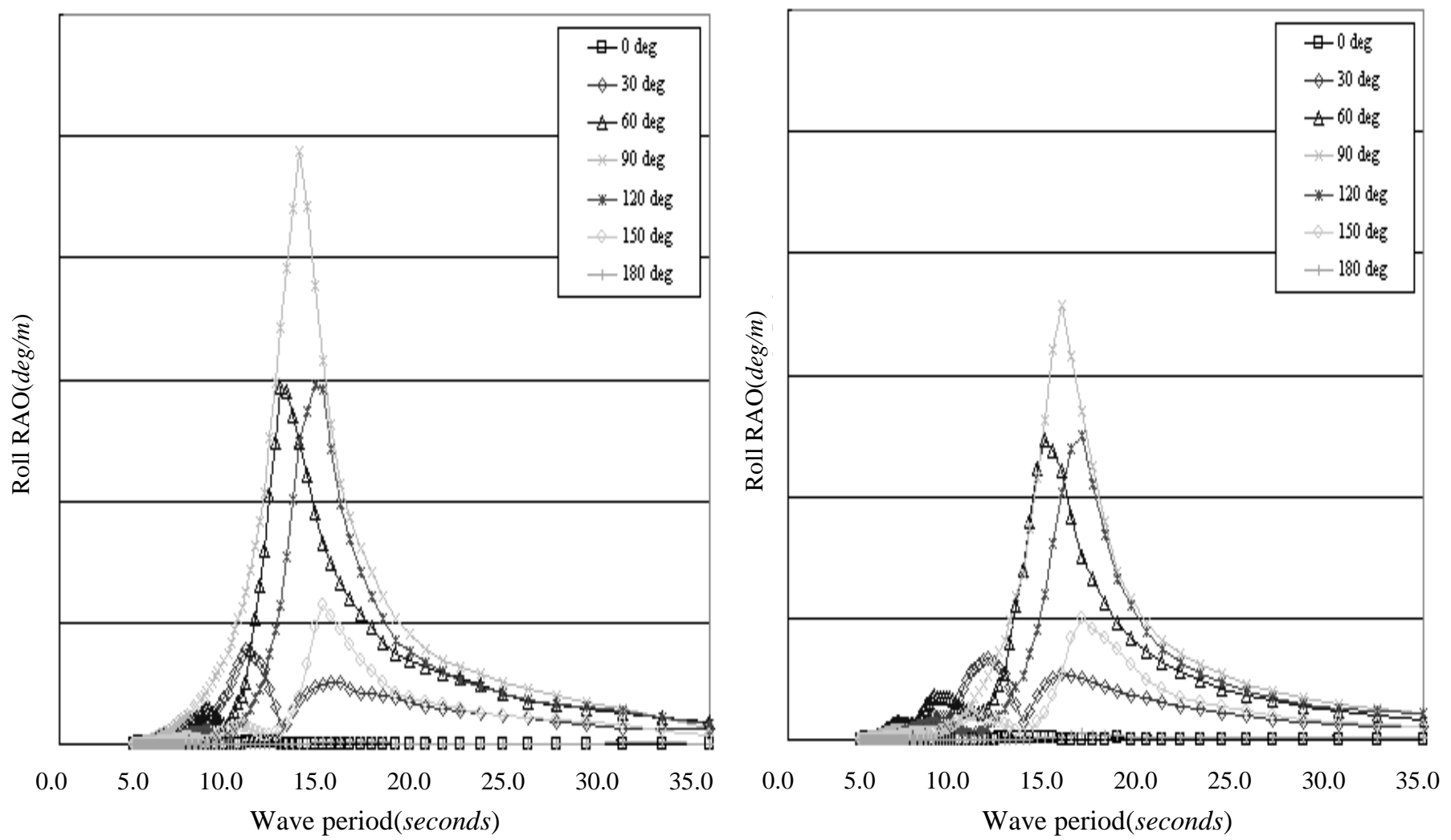

(b) ship B (ballast, full load)

Fig. 10 Roll motion RAOs 

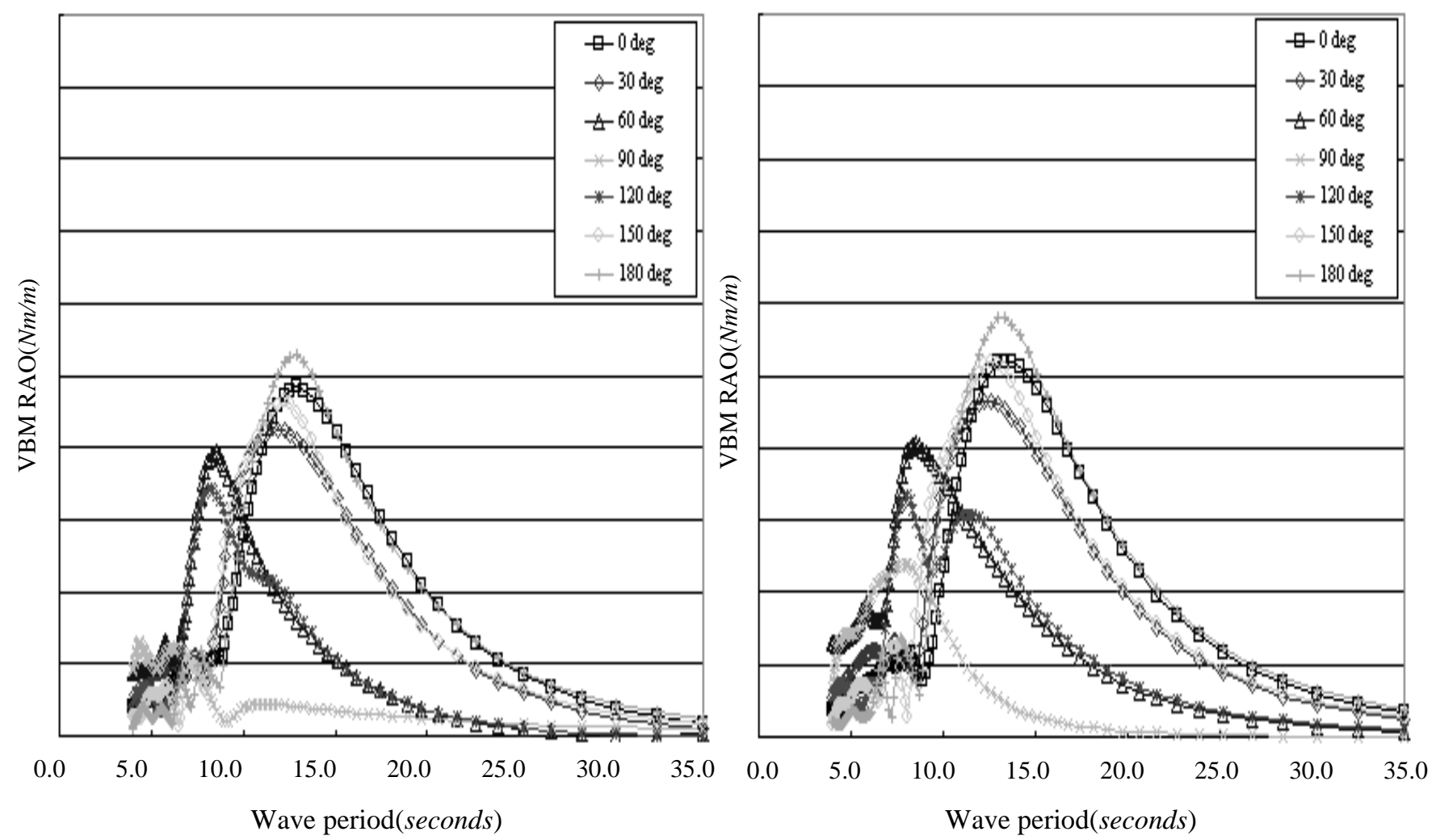

(a) ship A (ballast, full load)

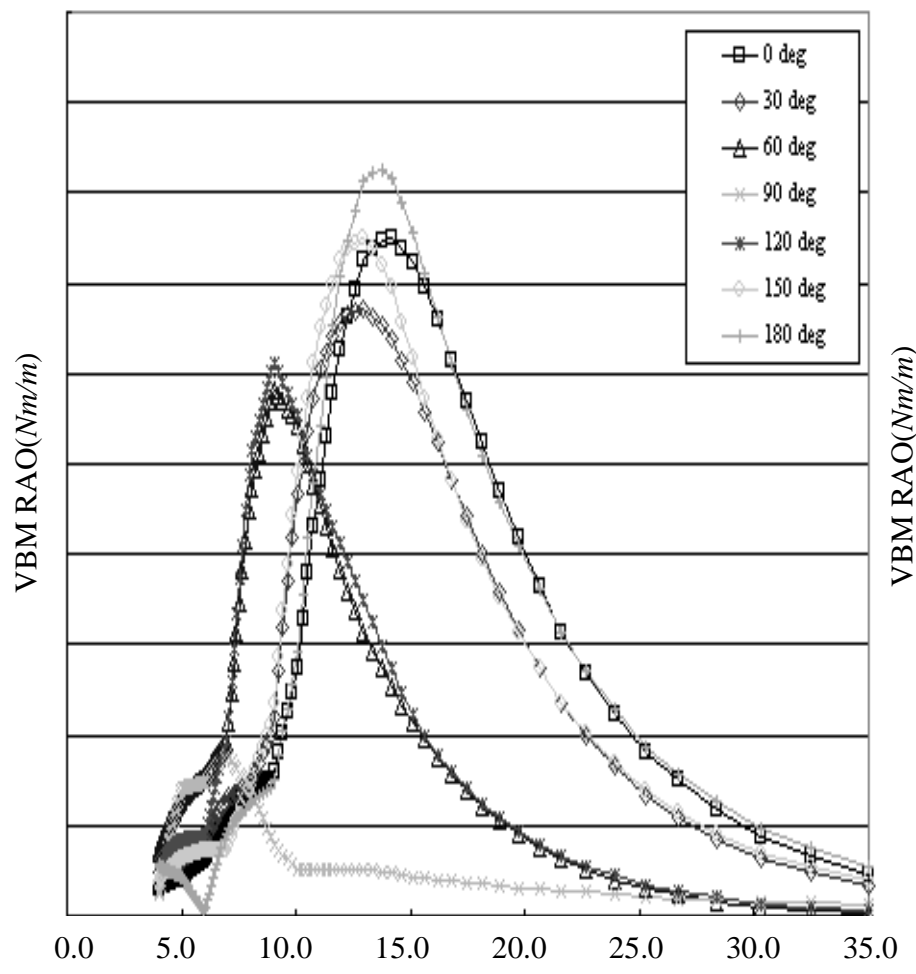

Wave period(seconds)

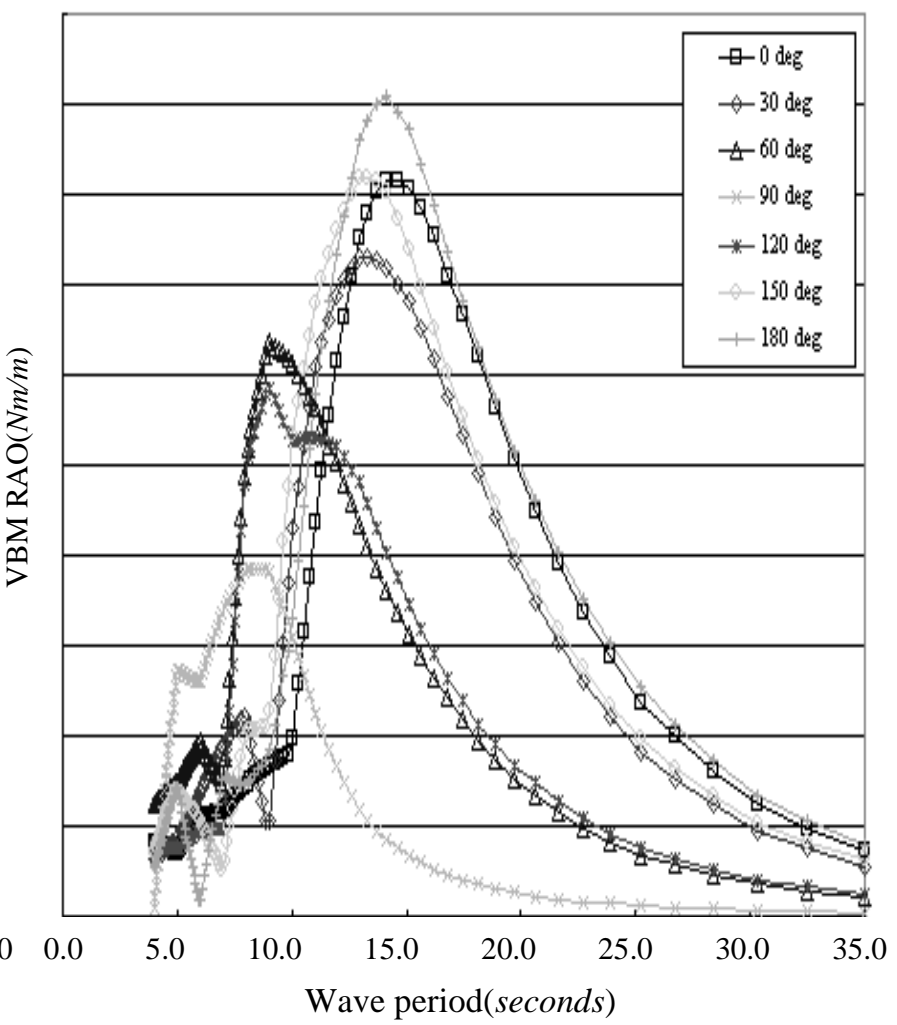

(b) ship B (ballast, full load)

Fig. 11 Vertical bending moment RAOs 


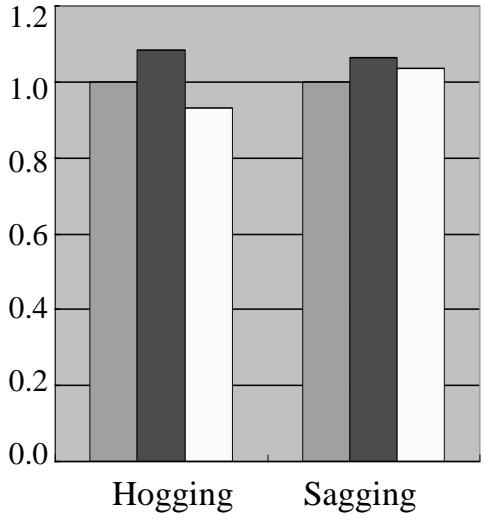

(a) ship A (ballast, full load)

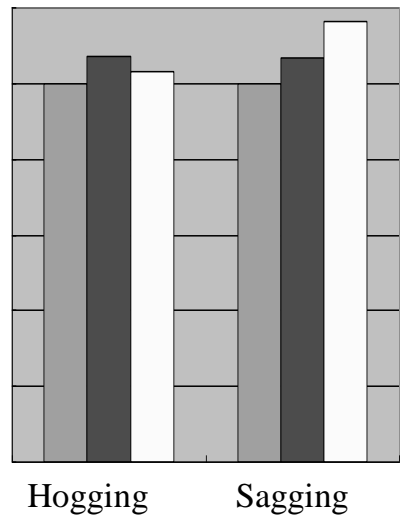

Hogging Sagging

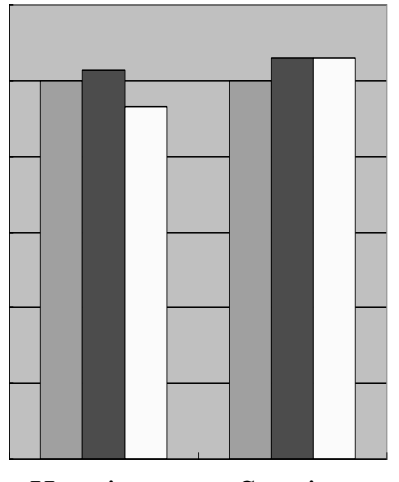

Hogging

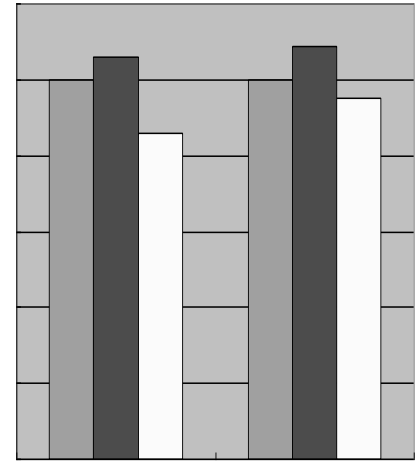

Hogging Sagging

(b) ship B (ballast, full load)

Fig. 12 Wave induced Vertical Bending Moment vs. Rule value ; Normalized by Linear Results.

Fig. 13 shows the snap shot of pressure distribution at maximum vertical bending moment in full loads condition. These pressure distributions are transferred to FE-model automatically for the structural analysis.
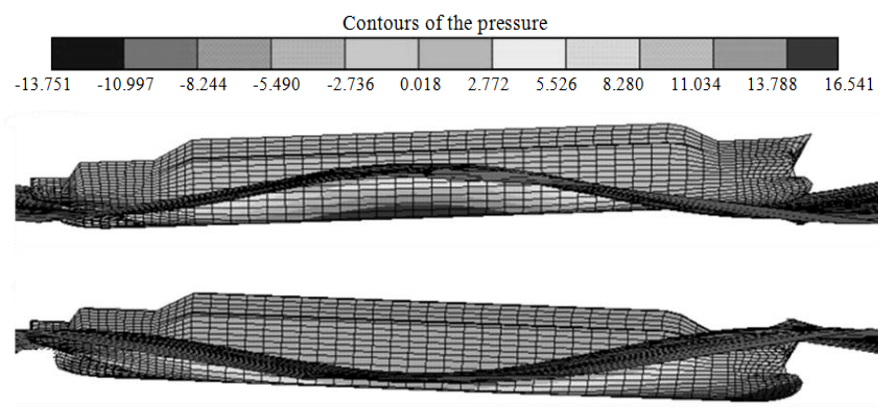

(a) Ship A (hogging, sagging)
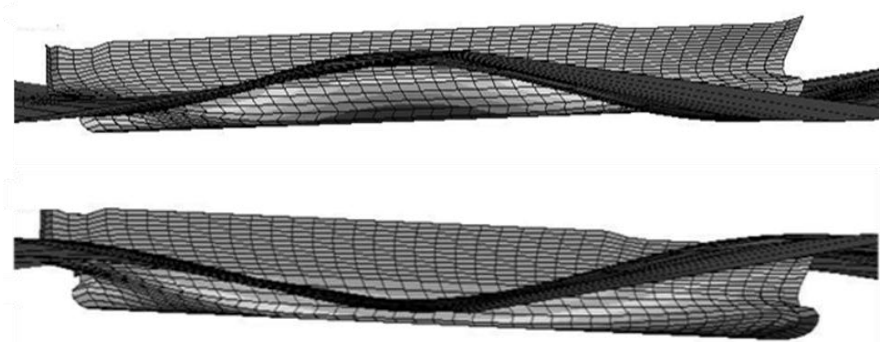

(b) Ship B (hogging, sagging)

Fig. 13 Snap shot of pressure distribution at maximum Vertical Bending Moment in full loads.

\section{Green water effect}

Fig. 14 shows the comparison of vertical bending moment with and without green water effect. The results show the vertical bending moments are more influenced by green water in sagging condition than in hogging condition due to green water loading on bow deck.

Green water effect on vertical bending moment is investigated at full load condition since water on deck occurs when the ship has lower freeboard. Fonseca and Guedes Soares(1998), and Mikami and Kashiwagi(2007) developed nonlinear strip theory with green water effect in time domain. In WASIM, green water effect is simulated as hydrodynamic loads on deck using a non-linear Froude Krylov pressure. When the panel mesh is created on deck area, the vertical bending moment including green water loads is calculated automatically (see Fig. 15).

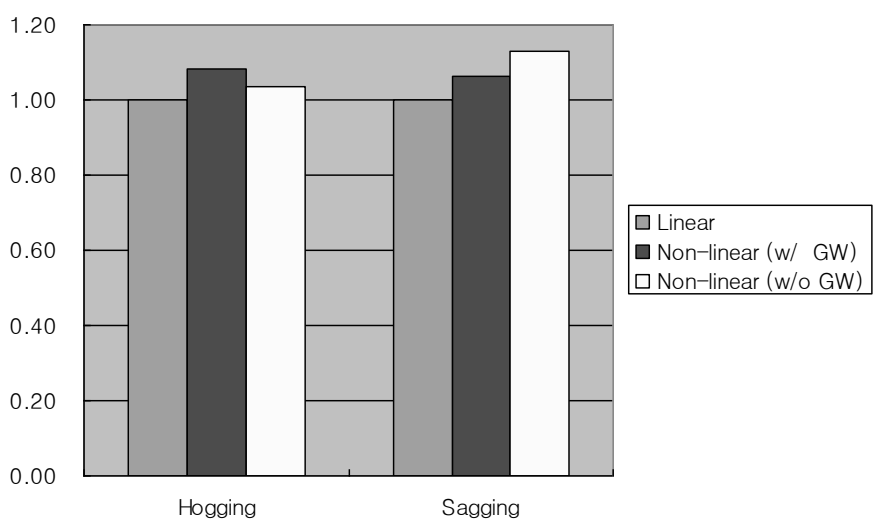

(a) Ship A (Full load)

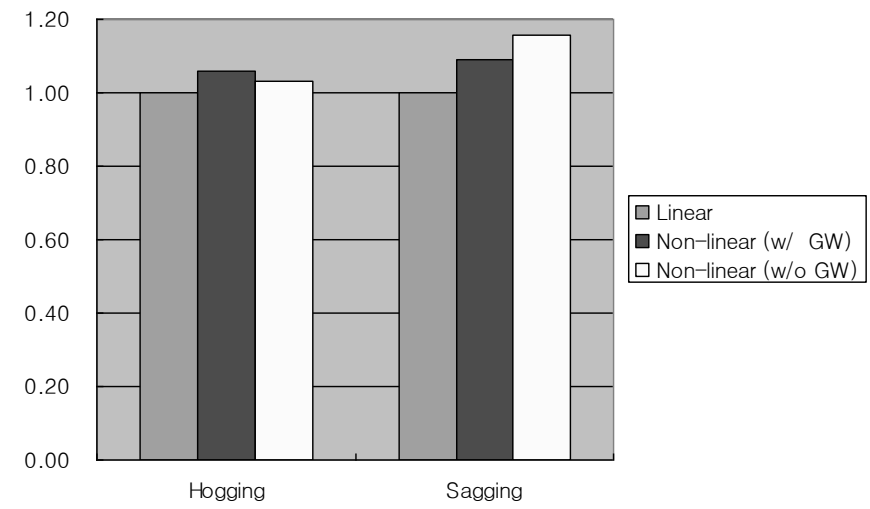

(b) Ship B (Full load)

Fig. 14 Vertical bending moment (w/ Green water) vs. Vertical Bending Moment (w/o Green water); Normalized by Linear Results. 

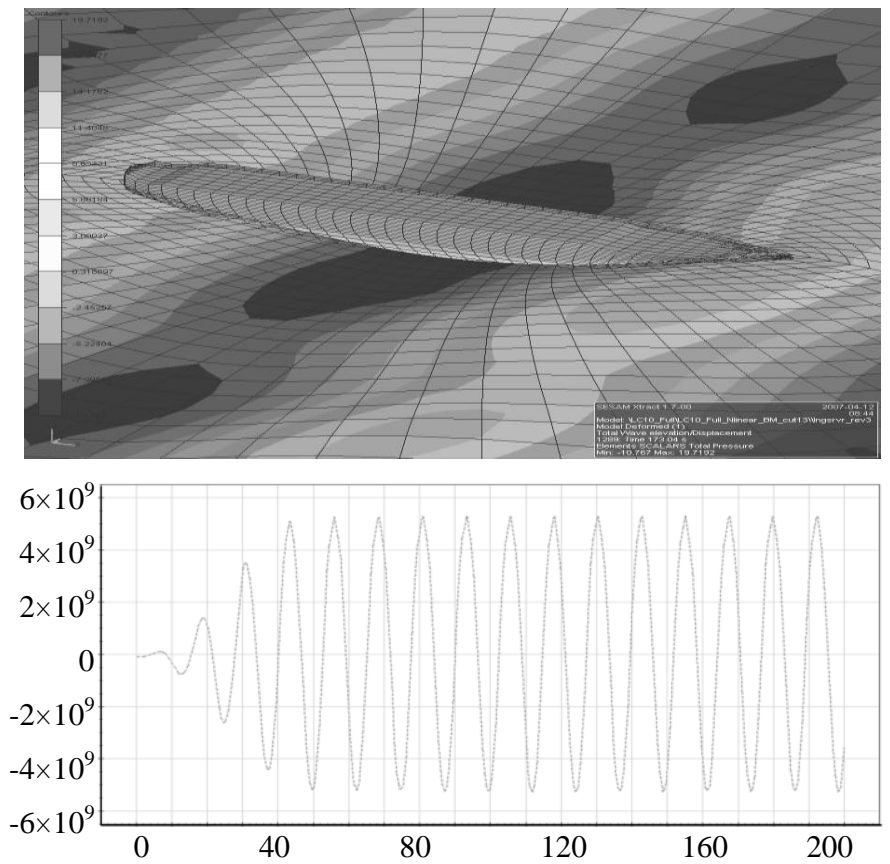

(a) w/o Green water
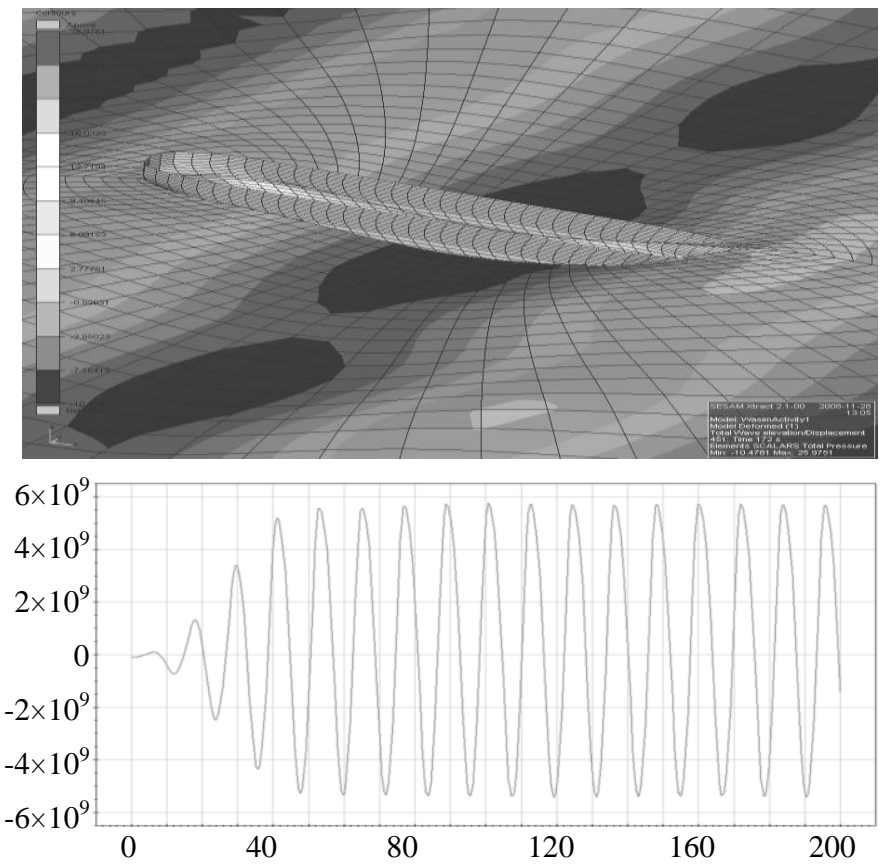

(b) w/ Green water

Fig. 15 Snap shot and time signal of Maximum Vertical Bending Moment

\section{CONCLUSIONS}

A numerical investigation, CSA-2, of wave induced motion and wave loads has been carried out in the design stage for two ocean going vessels. To evaluate the motion and wave loads RAOs of seakeeping characteristics of the vessels in regular waves, the motion analysis performed using a three-dimensional time domain motion program, WASIM. The loading conditions are selected from the loading manual booklet, which include normal ballast and full load condition and various loading conditions. In ULS, the linear extreme loads of return period of 20 years with North Atlantic wave scatter diagram are calculated for sectional wave loads along the ship length at 5 knots of forward speed. The non-linear design loads are calculated for selected design cases and design waves. The nonlinear design loads are higher than the linear and rule values in sagging and hogging condition.

Therefore, the nonlinear analysis is required to design the large vessels for the structural verification. Also, the wave induced vertical bending moments are more influenced by green water in sagging condition than in hogging condition due to green water loading on bow deck. For the robust design, without green water in vertical bending moment is recommended. However, it is necessary that the additional guide line whether consider green water or not in the wave induced vertical bending moment calculations.

\section{REFERENCES}

WASIM, 2004. User Manual. Wave Loads on Vessels with Forward Speed, DNV, 12 Aug. 2004.

WAVESHIP, 1993. User Manual, Wave Loads on Slender Vessels. DNV, 15 Oct. 1993.

POSTRESP, 2004. User Manual, DNV, 15 Nov. 2004.

DNV-RP-C205，2007. Environmental Conditions and Environmental Loads. April 2007. Norway.

Fonseca, N. and Guedes Soares, C., 1998. Time-domain Analysis of Large Amplitude Vertical motion and wave loads. Journal of the Ship research, 42(2), pp. 139-153.

Takashi, M. and Kashiwagi, M., A., 2007. Time-domain nonlinear strip method in view of elasticity of ship hull and green water on deck. Proc. of International Conference on Violent Flows (VF-2007), Fukuoka, Japan. 